\title{
Kaposi's sarcoma-associated herpesvirus (KSHV) serum DNA not associated with subsequent non-Hodgkin's lymphoma (NHL) risk
}

\author{
Dan Beachler ${ }^{1}$, Lan Lin Gellert ${ }^{2}$, Rich Ambinder², Lisa Jacobson'1, Gypsyamber D'Souza ${ }^{1 *}$ \\ From $12^{\text {th }}$ International Conference on Malignancies in AIDS and Other Acquired Immunodeficiencies \\ (ICMAOI) \\ Bethesda, MD, USA. 26-27 April, 2010
}

\section{Background}

Non-Hodgkin's lymphoma (NHL) is a diverse group of cancers, elevated in HIV-infected individuals. Kaposi's sarcoma-associated herpes virus (KSHV) is found in a subset of NHL tumors, and could therefore be a cause of NHL. However, antibody testing for KSHV has limited sensitivity and specificity and studies have not associated KSHV antibodies with NHL odds. KSHV DNA in serum is a more specific marker of KSHV infection.

\section{Methods}

We performed a nested case-control study in the Multicenter AIDS Cohort Study, including 155 incident NHL cases occurring between 1984 and 2006 and non-cancer controls matched by study entry and time at risk. KSHV DNA was tested in pre-diagnostic serum from within 5 years before diagnosis using real-time quantitative PCR.
Risk factors for NHL were evaluated with conditional logistic regression models.

\section{Results}

NHL cases were significantly more likely to have Kaposi sarcoma, and had more advanced HIV disease as indicated by lower CD4 cell count at study baseline and greater reduction in CD4 from baseline to HAART era than their matched controls (each $\mathrm{p}<0.01$ ). Detection of KSHV DNA in pre-diagnostic serum was more common among NHL cases than controls ( $14 \%$ vs. $6.5 \%, \mathrm{p}=0.03)$. However, among cases and controls who had detectable KSHV DNA, the median KSHV viral load (406 vs. 324, $\mathrm{p}=0.39$ ) was comparable. After adjusting for age, baseline CD4 cell count, and CD4 change, KSHV serum DNA was no longer significantly associated with odds of NHL $(\mathrm{OR}=1.5,95 \% \mathrm{CI}=0.53-3.9)$. Similarly null associations

Table 1 Comparison of KSHV DNA and KSHV seropositivity among 155 HIV-positive incident NHL cases compared to 155 HIV-positive matched controls

\begin{tabular}{lllll}
\hline OR (95\% CI) & N & Univariate & Multivariate \\
\hline KSHV serum DNA: $\geq 1$ copy detected & 310 & $2.3(1.1-5.1)$ & $1.5(0.53-3.9)$ \\
& Among subset with serum within 1 year before diagnosis & 130 & $1.2(0.37-3.9)$ & $0.81(0.14-4.7)$ \\
& Among subset without Kaposi sarcoma diagnosis & 216 & $4.0(1.13-14)$ & $1.9(0.37-9.6)$ \\
& Among those developing NHL after AIDS & 152 & $2.0(0.60-6.6)$ & $2.0(0.55-7.0)$ \\
KSHV antibodies: seroprevalent & 252 & $1.3(0.68-2.5)$ & $0.85(0.36-2.0)$ & \\
\hline
\end{tabular}

\footnotetext{
* Correspondence: gdsouza@jhsph.edu

'Department of Epidemiology, Johns Hopkins Bloomberg School of Public

Health, Baltimore, MD, USA

Full list of author information is available at the end of the article
} 
were observed among the subset of participants with serum within 1 year before diagnosis, by NHL sub-type, and when stratified by history of Kaposi sarcoma (Table 1). To better match for stage of disease, we performed a second analysis among 76 NHL cases who developed NHL after AIDS diagnosis, matching these cases to controls by time since AIDS diagnosis. KSHV serum DNA prevalence was similar among these AIDS NHL cases and matched controls ( $14 \%$ vs. $9.2 \%, \mathrm{p}=0.32)$. KSHV seroprevalence was also not associated with odds of NHL.

\section{Conclusions}

We found no significant independent association between KSHV DNA in pre-diagnostic serum with overall odds of NHL in this nested case control study. This research suggests that, similar to KSHV antibodies, KSHV serum DNA does not have predictive value for NHL risk and KSHV is not a primary cause of NHL in HIV-positive men who have sex with men.

\section{Acknowledgements}

This article has been published as part of Infectious Agents and Cancer Volume 5 Supplement 1, 2010: Proceedings of the $12^{\text {th }}$ International Conference on Malignancies in AIDS and Other Acquired Immunodeficiencies (ICMAOI). The full contents of the supplement are available online at http://www.biomedcentral.com/1750-9378/5?issue=S1.

\section{Author details}

'Department of Epidemiology, Johns Hopkins Bloomberg School of Public Health, Baltimore, MD, USA. ${ }^{2}$ Department of Oncology, Johns Hopkins

Hospital, Baltimore, MD, USA.

Published: 11 October 2010
Submit your next manuscript to BioMed Central and take full advantage of:

- Convenient online submission

- Thorough peer review

- No space constraints or color figure charges

- Immediate publication on acceptance

- Inclusion in PubMed, CAS, Scopus and Google Scholar

- Research which is freely available for redistribution

Submit your manuscript at www.biomedcentral.com/submit 